\section{Bullying and mental health in national school children}

As part of a wider study examining alcohol, tobacco and drug use in national school children in the midwest region researchers also examined bullying and children's selfesteem and depression levels. In the above study bullying was defined as follows; "We say a pupil is BEING BULLIED when another pupil or group of pupils say or do nasty or unpleasant things to him or her. It is also bullying when a student or group of students is teased repeatedly in a way he or she does not like or when they are deliberately left out of things. But it is not bullying when two pupils of about the same strength or power argue or fight. It is also not bullying when teasing is done in a friendly or playful way". This definition was taken from the Health Behaviour in School-aged Children study conducted by researchers in NUI, Galway. ${ }^{1}$

Children's self-esteem levels were measured using the 14 item self-esteem subscale from the child version of the Child Health Questionnaire (CHQ-CF87). Two depression inventories, the Children's Depression Inventory-Short Form (CDI-S) and the revised four item version of the Center for epidemiological Studies Depression Scale for Children (CES-DC), measured depressive symptomatology in national school children.

Schools were selected using a stratified random sampling technique, stratified according to the area in which the school was located. Of the 50 national schools in the midwest region (Limerick City, Limerick County, County Clare and Tipperary $\mathrm{NR}$ ) approached to take part in this study, 43 national schools agreed to partake in this research. Four schools declined to participate, while the remaining three schools were newly established and therefore had no fifth or sixth class pupils. Schools were located in both rural and urban settings. A total of 1,255 children ( 574 boys and 681 girls) attending mainstream primary schools took part in this study.

Active parental consent was a condition of inclusion in this study. Children were aged between 10-13 years, with the mean age of respondents being 11.5 years ( $s d=0.73$ ). The response rate was $76.2 \%$, this rate is inclusive of nonparticipating schools.

Three separate independent samples t-tests were conducted to compare CESDC scores, CDI-S scores and CHQ- CF87 scores respectively for those who purport to be victims of bullying and for those who claim they have not been victims of bullying. Results revealed that there was a significant difference in the scores of respondents who have and have not been bullied on all three measures. There was a significant difference ( $t(135)=-6.16, p=.001)$ in the CESDC score, the CDI-S scores $(t(123)=-7.54, p=.001)$ and $\mathrm{CHQ}$-Cf87 self-esteem scores $(t(123)=6.39, p=.001)$.

Previous research has demonstrated that bullying is related to negative psychosocial functioning among children who are victimised, including lowered self-esteem,,$^{2 \cdot 4}$ and higher rates of depression. ${ }^{2,3,5}$

The above results demonstrate that there is a significant relationship between self-esteem and depression scores of
Mean scores, standard deviation and sample size for the CESDC, CDI-S and CHQ- GF87 for those who have and have not been bullied

\begin{tabular}{lcccc} 
Scale used & \multicolumn{2}{c}{ Victims of bullying } & \multicolumn{2}{c}{ Not victims of bullying } \\
& Mean (n) & Std.Deviation & Mean (n) & Std.Deviation \\
CESDC & $3.87(117)$ & 2.15 & $3.87(1079)$ & 2.55 \\
CDI-S & $4.46(113)$ & 3.66 & $1.80(978)$ & 2.42 \\
CHQ-Cf87-self esteem scale & $75.94(112)$ & 16.91 & $86.42(1011)$ & 11.92
\end{tabular}

older national school children who have and have not been bullied. Relations may be causal but in a cross-sectional study such as this one it is impossible to unravel the temporal sequence of victimisation and self-esteem and depression levels. Nonetheless, these results indicate that a significant minority of students assert that they are victims of bullying.

Bullying is an aspect of school life that impacts on a pupil's social, emotional, psychological and educational development and therefore it is critical that schools implement policies and programmes dealing with bullying. Positive skills such as problem solving and coping skills should be instigated in all schools.

Fiona Meehan,

Department of Public Health, HSE Mid-West Area

Frank Houghton,

Limerick Institute of Technology

Hillary Cowley \& Kevin Kelleher, Department of Public Health, HSE Mid-West Area.

References

1. Kelleher C NicGabhainn S. Friel S. National Health and Lifestyle Surveys: Survey of Lifestyle attitudes and Nutrition (SLAN) and the Irish Health Behaviour in School-aged Children Survey (HBSC). Centre for Health Promotion Studies, NUI, Galway, 2003.

2. Hodges E, Perry, DG. Victims of peer abuse: An Overview. Journal of Emotional and Behavioural problems 1996; 5: 23-28

3. Olweus D. Bullying at school: What we know and what we can do? Blackwell, New York, 1993 4. Rigby K, Slee PT. Dimensions of interpersonal relations among Australian school children and their implications for psychological well-being. Journal of Social psychology 1993: $133: 33.42$ 5. Craig WM. The relationship among bullying, victimisation, depression, anxiety, and aggression in elementary school children. Personality and individual Differences 1998: 24: 123-130

\section{Absence of dissociative disorders in Irish journals}

We recently voiced concern at the failure of clinical psychology and psychiatry training programs in Ireland to provide contemporary phenomenological and treatment information on dissociative disorders. ${ }^{1}$ This gap in training is discordant with empirical literature on the prevalence of dissociative disorders and arguably leads to a failure to detect and therefore successfully treat these conditions.

Curious about whether lack of education on dissociative disorders in professional training was reflected in Irish psychological and psychiatric publications, we conducted a small bibliographic study. Selected for this study were the following Irish psychology- and psychiatry-related journals: Irish Journal of Education, Irish Journal of Medical Science, Irish Journal of Psychiatry, Irish Journal of Psychological Medicine, Irish Journal of Psychology, Irish Journal of Psychotherapy and Irish Journal of Psychotherapy and Psychosomatic Medicine. Searches were conducted using the PsycINFO database in January 2005. The database selected covered the time period from 1872 to January week 3, 2005. Keywords used to iden- 